\title{
A comparative study of hyperfine interactions in Aurivillius compounds prepared by mechanical activation and solid-state sintering
}

Mariusz Mazurek, Elżbieta Jartych

\begin{abstract}
X-ray diffraction and Mössbauer spectroscopy techniques were used to study the structure and hyperfine interactions of multiferroic Aurivillius compounds $\mathrm{Bi}_{m+1} \mathrm{Ti}_{3} \mathrm{Fe}_{m-3} \mathrm{O}_{3 m+3}$. Samples were synthesized by two methods, that is, the solid-state sintering at various temperatures and mechanical activation in a high-energy ball mill. The compounds were obtained from a mixture of three polycrystalline powder oxides, that is, $\mathrm{TiO}_{2}, \mathrm{Fe}_{2} \mathrm{O}_{3}$ and $\mathrm{Bi}_{2} \mathrm{O}_{3}$. At room temperature, the Aurivillius compounds are paramagnetic materials with orthorhombic crystal structure. The $c$ lattice parameter of the unit cell depends linearly on the $m$ - number of layers with perovskite-like structure. Based on the Mössbauer studies, it is concluded that the hyperfine interactions parameters do not change with $m$ number.
\end{abstract}

Keywords: Aurivillius compounds • solid-state sintering • mechanical activation • Mössbauer spectroscopy • hyperfine interactions

M. Mazurek, E. Jartych ${ }^{\bowtie}$

Institute of Electronics and Information Technology,

Lublin University of Technology,

38A Nadbystrzycka Str., 20-618 Lublin, Poland,

Tel.: +48 81538 4464, Fax: +48 81538 4312,

E-mail: e.jartych@pollub.pl

Received: 4 July 2016

Accepted: 5 October 2016

\section{Introduction}

Multiferroic materials, exhibiting simultaneously ferroelectric and magnetic arrangement, have been attracting considerable attention during the last years. Much of the corresponding research is motivated by the great potential of these materials for non-volatile data storage, sensor applications, and many other areas of technology [1]. However, materials that exhibit multiferroic properties at room temperature, and are thus suitable candidates for future device applications, are still extremely scarce. Therefore, the search for alternative materials with robust multiferroic properties at room temperature is of high relevance.

A promising class of materials for this purpose are the so-called Aurivillius phases, first reported in [2]. Multiferroic Aurivillius compounds are described by the chemical formula $\mathrm{Bi}_{m+1} \mathrm{Ti}_{3} \mathrm{Fe}_{m-3} \mathrm{O}_{3 m+3}$. They have a layered structure, in which fluorite-like layers $\left\{\left(\mathrm{Bi}_{2} \mathrm{O}_{2}\right)^{2+}\right\}$ are stacked alternately with perovskite-like slabs $\left\{\left(\mathrm{Bi}_{m+1} \mathrm{Fe}_{m-3} \mathrm{Ti}_{3} \mathrm{O}_{3 m+1}\right)^{2-}\right\}$. The value of $m$ is the number of perovskite-like layers per block and may take integer or fractional values, moreover $m$ is less than 13 [3]. The structure, electric properties, and thermal stability of the Aurivillius compounds are relatively well recognized and described. However, their magnetic properties are not well known and reported in the literature.

The main aim of the present work was to find a relationship between the parameters of hyperfine 
interactions and the number $m$ of perovskite-like layers of the Aurivillius compounds synthesized by solid-state sintering and mechanical activation methods. Due to decreasing of thermal stability of the Aurivillius compounds along with increasing of the $m$ number, the research was focused on compounds with $m=4-8$ layers.

Systematic measurements were performed using X-ray diffraction (XRD) and Mössbauer spectroscopy (MS) to establish the crystalline and hyperfine structure of the examined materials.

\section{Experimental details}

The Aurivillius $\mathrm{Bi}_{m+1} \mathrm{Ti}_{3} \mathrm{Fe}_{m-3} \mathrm{O}_{3 m+3}$ compounds were prepared by the traditional method of synthesis in the solid state and two different variants of mechanical activation. The synthesis of $\mathrm{Bi}_{m+1} \mathrm{Ti}_{3} \mathrm{Fe}_{m-3} \mathrm{O}_{3 m+3}$ compounds with various $m$ proceeded as per the following reaction:

$$
\begin{aligned}
6 \mathrm{TiO}_{2}+ & (m+1) \mathrm{Bi}_{2} \mathrm{O}_{3}+(m-3) \mathrm{Fe}_{2} \mathrm{O}_{3} \\
& \rightarrow 2 \mathrm{Bi}_{m+1} \mathrm{Ti}_{3} \mathrm{Fe}_{m-3} \mathrm{O}_{3 m+3}
\end{aligned}
$$

In the sintering method, the studied Aurivillius compounds were prepared from the oxides of bismuth, titanium and iron (all $99.9 \%$ purity) in the appropriate stoichiometric proportions. Powders were wet-mixed with ethyl alcohol $\mathrm{C}_{2} \mathrm{H}_{5} \mathrm{OH}$ in polyamide containers in the planetary ball mill for $t=24 \mathrm{~h}$. Zirconium-yttrium balls with a diameter of $10 \mathrm{~mm}$ were used as grinding media. The mixtures were then dried and pressed on a hydraulic press under a pressure $p$ of $30 \mathrm{MPa}$. During pressing, the discs with a diameter of $20 \mathrm{~mm}$ were formed. The obtained green bodies were then fired in air at temperature $T=993 \mathrm{~K}$ for $t=2 \mathrm{~h}$. In the next step, the discs were re-milled, pressed under $p=60$ MPa into discs with a diameter of $10 \mathrm{~mm}$, and then sintered at $1123 \mathrm{~K}$ (for $m=4,6,7,8)$ and $1253 \mathrm{~K}(m=5)$ for $2 \mathrm{~h}$. The heating and cooling rates were $5 \mathrm{~K} \cdot \mathrm{min}^{-1}$. Next, the samples were furnace-cooled to room temperature.

In the mechanical activation (MA) methods, the stoichiometric amounts of bismuth, titanium, and iron oxides were placed into the container of a Fritsch P5 Pulverisette planetary ball mill. The vial and balls were made with hardened steel. The ball-to-powder weight ratio was 10:1. In the first (MA I) variant, all oxides were milled together under an air atmosphere up to $50 \mathrm{~h}$. After milling, the thermal treatment of the mechanically activated compounds was performed in air using $1 \mathrm{~h}$ lasting isothermal annealing in a furnace at $1073 \mathrm{~K}$. The second, modified method (MA II) was performed as follows: (1) component oxides were milled in air separately up to $10 \mathrm{~h}$; next (2), the oxides were mixed and milled together in air during $50 \mathrm{~h}$; (3) after the milling process, the powders were thermally treated by $1 \mathrm{~h}$ lasting isothermal annealing in air at $1073 \mathrm{~K}$ in a furnace for $1 \mathrm{~h}$. After annealing, all the samples were cooled with a rate of $5 \mathrm{~K} \cdot \mathrm{min}^{-1}$ to room temperature.

The crystalline structure of the sintered samples was tested using the Philips PW3710 diffractometer with $\mathrm{CoK}_{\alpha}$ radiation $\left(\lambda=1.789 \times 10^{-10} \mathrm{~m}, \Theta-2 \Theta\right.$ geometry, angle range $2 \Theta=10-110^{\circ}$, scan step size $\Delta 2 \Theta=0.01^{\circ}$, scan step time $t=8 \mathrm{~s}$ ), while the mechanically activated specimens were examined by the Philips PW 1830 diffractometer with $\mathrm{CuK}_{\alpha}$ radiation $\left(\lambda=1.541 \times 10^{-10} \mathrm{~m}, \Theta-2 \Theta\right.$ geometry, angle range $2 \Theta=20-100^{\circ}$, scan step size $\Delta 2 \Theta=0.02^{\circ}$, scan step time $t=5 \mathrm{~s}$ ). The phase and structural analysis of the registered XRD patterns was performed with a PANalytical X'Pert HighScore Plus program equipped with the ICSD data base using the Rietveld refinement method.

The measurements of ${ }^{57} \mathrm{Fe}$ Mössbauer spectra were carried out in a transmission geometry using a constant-acceleration POLON spectrometer. The source of $14.4 \mathrm{keV}$ gamma rays was ${ }^{57} \mathrm{Co}$ in a rhodium or a chromium matrix. The spectrometer was calibrated using $\alpha-\mathrm{Fe}$ foil. All the values of isomer shifts described later are given in relation to $\alpha$-Fe at room temperature.

\section{Results and discussion}

The results of XRD and MS studies of the Aurivillius compounds for $m=4-8$ obtained by solid-state

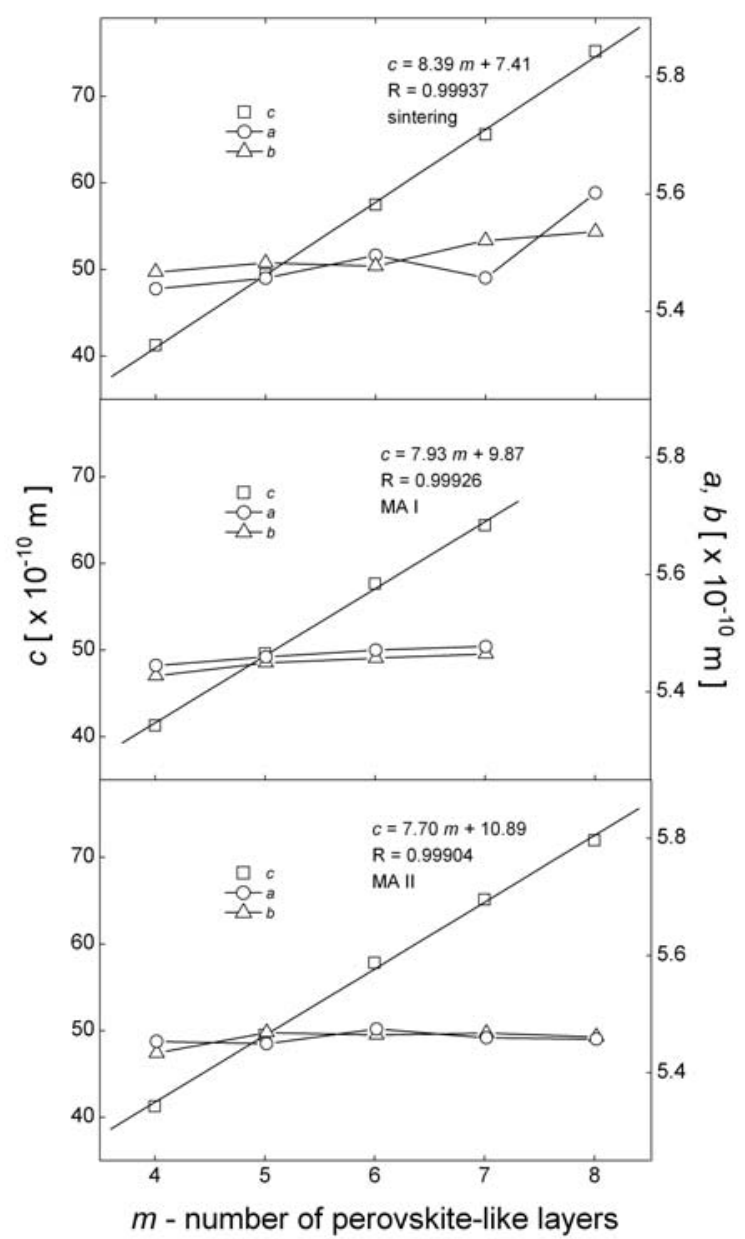

Fig. 1. Lattice parameters $a, b$ and $c$ of the Aurivillius compounds as a function of the number of perovskite-like layers $m$; the straight lines are a least-squares fitting with the correlation coefficient $R$; the uncertainties for lattice parameters are within the area of the graphical symbol. 
sintering and mechanical activation have already been reported in details in our earlier works [4-10]. It was shown that only $\mathrm{Bi}_{5} \mathrm{Ti}_{3} \mathrm{FeO}_{15}$ compound is a single-phase material, while the other Aurivillius compounds $(m=5-8)$ contain adjacent phases (with $m \pm 1$ ) besides the main phase [6,11]. All the studied compounds have orthorhombic unit cell. Figure 1 presents lattice parameters $a, b, c$ determined for the main phase (the compound with suitable $m$ ) as a function of $m$ number for sintered and mechanically activated Aurivillius compounds.

In all the cases, the values of $a$ and $b$ parameters do not change with the $m$ number, being in the range of 5.4-5.6 $\times 10^{-10} \mathrm{~m}$. With increasing $m$ number, the lattice parameter $c$ increases from about $42 \times$ $10^{-10} \mathrm{~m}$ for $m=4$ up to $75 \times 10^{-10} \mathrm{~m}$ for $m=8$. The observed linear dependences of $c$ parameter on $m$ number allow estimating the average thickness of perovskite-like layer as $p \cong(4.11 \pm 0.01) \times 10^{-10} \mathrm{~m}$ for sintered Aurivillius compounds and $p \cong(4.13$ $\pm 0.01) \times 10^{-10} \mathrm{~m}(\mathrm{MA} \mathrm{I})$ and $p \cong(4.10 \pm 0.01) \times$ $10^{-10} \mathrm{~m}$ (MA II) for mechanically activated samples. The lattice parameters of the $\mathrm{Bi}_{m+1} \mathrm{Ti}_{3} \mathrm{Fe}_{m-3} \mathrm{O}_{3 m+3}$ compounds prepared in the present work by different methods are comparable with one another and they agree very well with parameters published in [3].

Room-temperature Mössbauer spectra collected for sintered and mechanically activated $\mathrm{Bi}_{m+1} \mathrm{Ti}_{3} \mathrm{Fe}_{m-3} \mathrm{O}_{3 m+3}$ compounds are presented in Fig. 2. For all the sintered samples, the Mössbauer spectra have the shape of doublet confirming paramagnetic properties of the material at room temperature (Fig. 2a). In the case of the MA I method, pure Aurivillius compound was produced only for $m=6$ (Fig. 2b). All the other MS spectra of the Aurivillius compounds consisted of the sextet and the doublet. The six-line sub-spectrum is characterized by the following hyperfine interactions parameters: isomer shift IS $=0.38(1) \mathrm{mm} \cdot \mathrm{s}^{-1}$, quadrupole shift $2 \varepsilon=$ $-0.21(4) \mathrm{mm} \cdot \mathrm{s}^{-1}$ and induction of hyperfine magnetic field $B_{\mathrm{hf}}=51.36(3) \mathrm{T}$. These values are characteristic of hematite [12]. It may be concluded that in the MA I method, not a whole amount of hematite reacted with other oxides. This may indicate that the temperature of thermal treatment was too low. In the case of MA II method (Fig. 2c), the desired Aurivillius compounds were formed and they were all paramagnetic at room temperature. There was no trace of the hematite component.

All MS spectra were numerically fitted assuming two ${ }^{57} \mathrm{Fe}$ positions in the structure of the Aurivillius compound (the structural model was described elsewhere in $[5,11])$. Iron ion may be located at the Ti site, that is, position inside the oxygen octahedron (B site in perovskite $\mathrm{ABO}_{3}$ structure). Two non-equivalent octahedral positions of $\mathrm{Fe}^{3+}$ ions may be distinguished in the structure of the Aurivillius compound, that is, in the centre of the inner B1 oxygen octahedron within the perovskite-like block and in the centre of the outer $\mathrm{B} 2$ octahedron adjacent to the fluorite-like $\left\{\left(\mathrm{Bi}_{2} \mathrm{O}_{2}\right)^{2+}\right\}$ layer $[5,11]$. Thus, the two doublets, D1 and D2, fitted to the MS spectra corresponded to the two Fe sites mentioned above. Figure 3 presents a juxtaposition of IS and

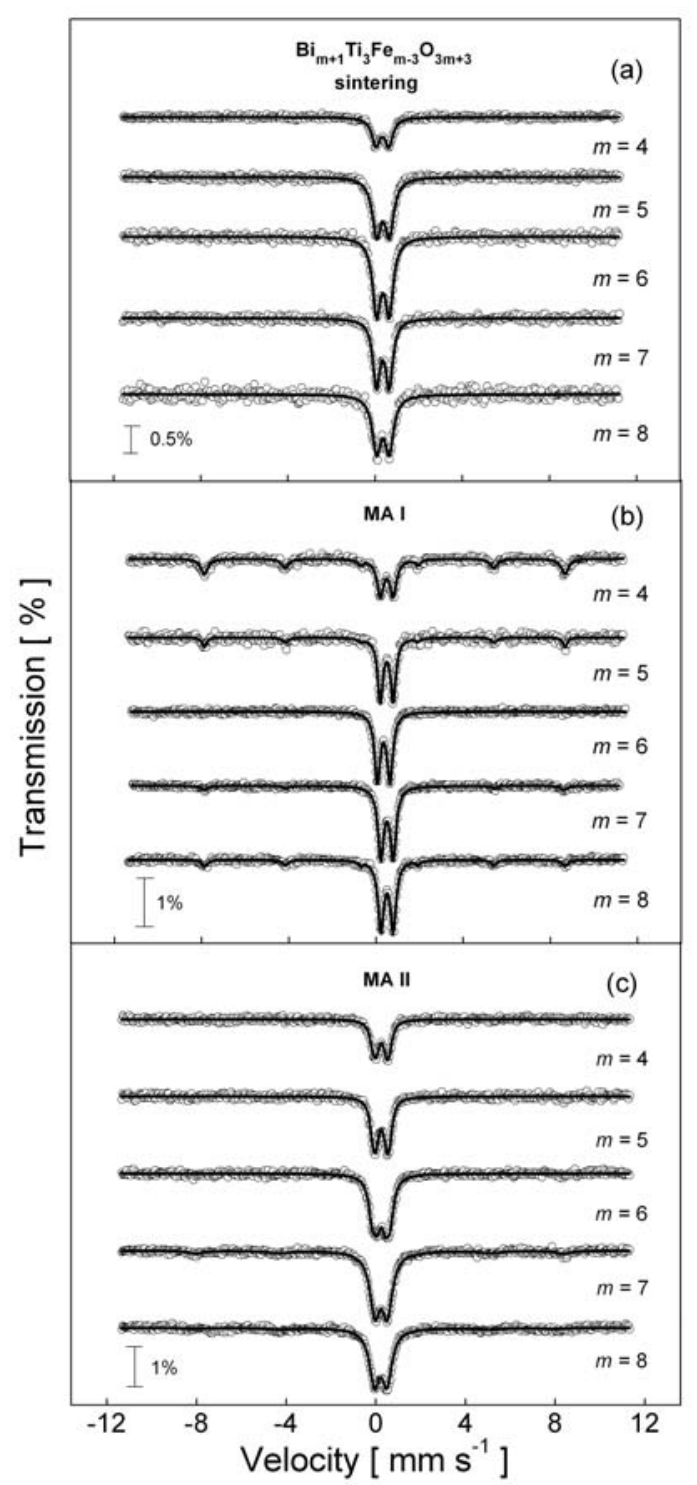

Fig. 2. Fitted room-temperature Mössbauer spectra of $\mathrm{Bi}_{m+1} \mathrm{Ti}_{3} \mathrm{Fe}_{m-3} \mathrm{O}_{3 m+3}$ compounds (a) after sintering, (b) after MA I process and (c) after MA II process.

QS parameters of doublets D1 and D2 as a function of the $m$ number in a given compound, prepared by sintering and mechanical activation methods.

It may be observed that all IS values are very similar to each other and they are independent of the number of perovskite-like layers (Fig. 3a). Similar values of IS (about $0.35 \mathrm{~mm} \cdot \mathrm{s}^{-1}$ ) for both B1 and B2 positions is justified because the nearest surrounding of ${ }^{57} \mathrm{Fe}$ nuclei is practically the same $\left(\mathrm{Fe}^{3+}\right.$ ions at B1 and B2 sites are surrounded by six oxygen ions in the first coordination sphere and by eight bismuth ions in the second sphere). Slight differences in the IS values for the given $m$ number may be due to the differences in the third coordination sphere (in which the ions of Fe and Ti occupy the crystallographic sites accordingly, with the chemical composition of the Aurivillius compound).

In the case of QS parameter, it can be stated that for B1 position, QS values stay between $0.35-0.50 \mathrm{~mm} \cdot \mathrm{s}^{-1}$ and for B2 position, between $0.65-0.80 \mathrm{~mm} \cdot \mathrm{s}^{-1}$ (Fig. 3b). The QS parameter 

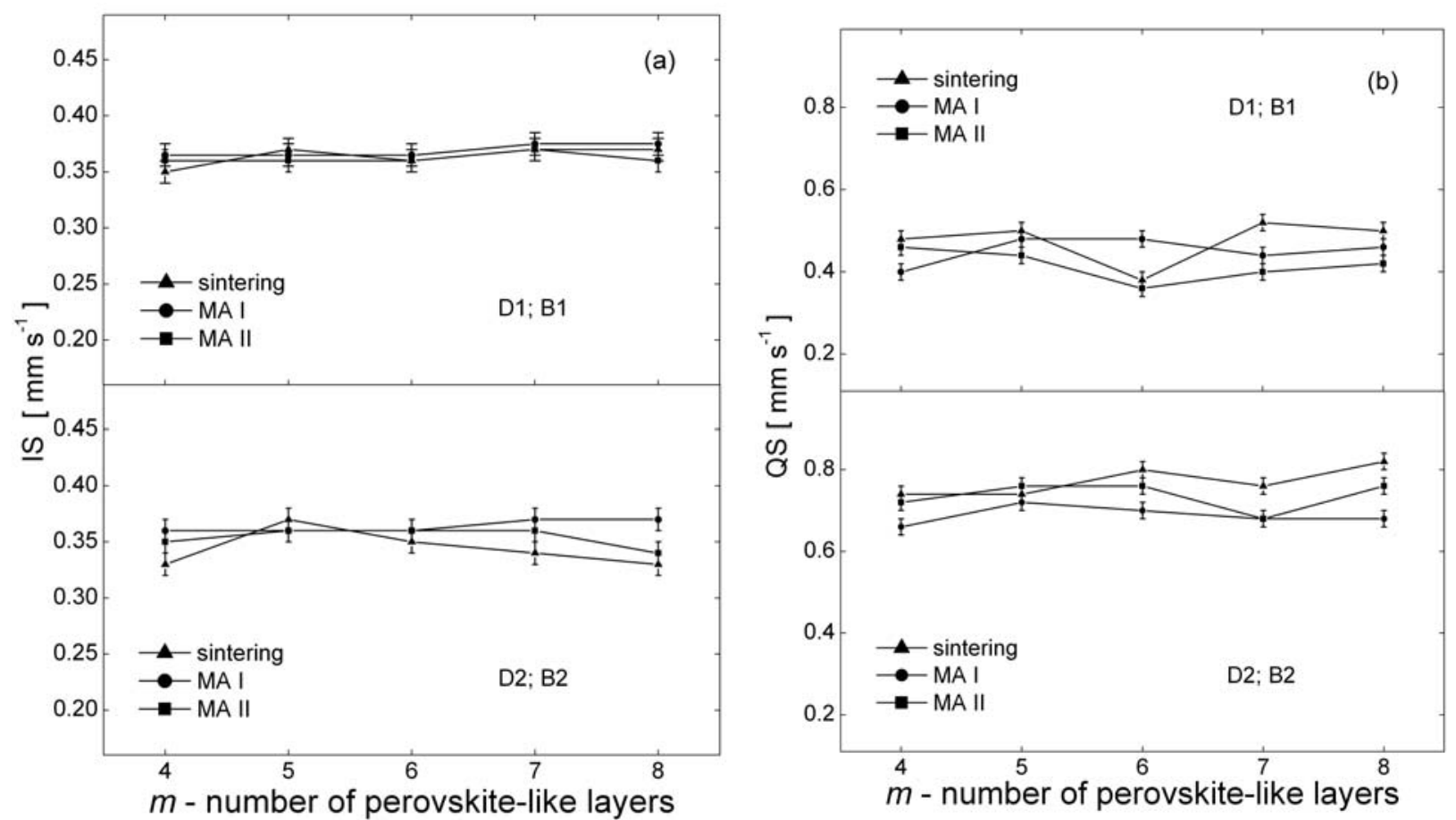

Fig. 3. Dependence of (a) isomer shift, IS, and (b) quadrupole splitting, QS, of two doublets D1 and D2 on $m$ - number of perovskite-like layers in Aurivillius compounds prepared by sintering and mechanical activation methods.

reflects crystal symmetry. QS values for positions $\mathrm{B} 2$ are higher than for B1 because near the fluorite-like layer, the electric field gradient is higher than inside the perovskite-like block (crystal symmetry is lower in the case of B2 positions). As in the case of IS, the number of perovskite-like layers practically does not affect the values of QS parameter. Visible differences in the QS values for a given $m$ number result from structural imperfections of the examined compounds. When comparing the values of IS and QS parameters for the Aurivillius compounds prepared with different methods described above, it can be concluded that hyperfine interactions parameters are similar to each other. Existing differences in IS and QS values result from differences in the samples microstructure.

\section{Conclusions}

Summarizing the obtained results, it may be stated that both X-ray diffraction and Mössbauer spectroscopy techniques allowed us to monitor the process of producing the Aurivillius compounds and get the knowledge about structure and hyperfine interactions of the studied materials. Comparing the hyperfine interaction parameters of the $\mathrm{Bi}_{m+1} \mathrm{Ti}_{3} \mathrm{Fe}_{m-3} \mathrm{O}_{3 m+3}$ compounds prepared by sintering, MA I and MA II methods, it can be concluded that the obtained values of IS and QS parameters practically do not vary with the number of perovskite-like layers.

The comparison of structural and magnetic properties of the Aurivillius compounds produced by the conventional solid-state sintering and mechanosynthesis allows us to conclude that proper mechanical activation method, namely MA II variant, can be treated as an alternative way of producing the mul- tiferroic $\mathrm{Bi}_{m+1} \mathrm{Ti}_{3} \mathrm{Fe}_{m-3} \mathrm{O}_{3 m+3}$ compounds. Moreover, the variant of mechanical activation described above allows producing the Aurivillius compounds at lower temperature, at least by about $50 \mathrm{~K}$, in comparison with materials made by conventional solid-state sintering method.

\section{References}

1. Zvezdin, A. K., Logginov, A. S., Meshkov, G. A., \& Pyatakov, A. P. (2007). Multiferroics: promising materials for microelectronics, spintronics, and sensor technique. Bull. Russ. Acad. Sci.: Physics, 71(11), 1561-1562. DOI: 10.3103/S1062873807110263.

2. Aurivillius, B. (1949). Mixed bismuth oxides with layer lattices. Ark. Kemi., 54(1), 463-471.

3. Lomanova, N. A., Morozov, M. I., Ugolkov, V. L., \& Gusarov, V. V. (2006). Properties of Aurivillius phases in the $\mathrm{Bi}_{4} \mathrm{Ti}_{3} \mathrm{O}_{12}-\mathrm{BiFeO}_{3}$ system. Inorg. Mater., 42, 189-195. DOI: 10.1134/s0020168506020142.

4. Jartych, E., Mazurek, M., Lisińska-Czekaj, A., \& Czekaj, D. (2010). Hyperfine interactions in some Aurivillius $\mathrm{Bi}_{m+1} \mathrm{Ti}_{3} \mathrm{Fe}_{m-3} \mathrm{O}_{3 m+3}$ compounds. I. Magn. Magn. Mater., 322, 51-55. DOI: 10.1016/j. jmmm.2009.08.022.

5. Jartych, E., Pikula, T., Mazurek, M., Franus, W. Lisińska-Czekaj, A., Czekaj, D., Oleszak, D., Surowiec, Z., Akseńczuk, A., \& Calka, A. (2016). Structure and magnetic properties of $\mathrm{Bi}_{5} \mathrm{Ti}_{3} \mathrm{FeO}_{15}$ ceramics prepared by sintering, mechanical activation and EDAMM process. A comparative study. Arch. Metall. Mater., 61, 869-874. DOI: 10.1515/amm-2016-0147.

6. Jartych, E., Pikula, T., Mazurek, M., Lisińska-Czekaj, A., Czekaj, D., Gąska, K., Przewoźnik, J., Kapusta, C., \& Surowiec, Z. (2013). Antiferromagnetic spin glass-like behavior in sintered multiferroic Aurivillius $\mathrm{Bi}_{m+1} \mathrm{Ti}_{3} \mathrm{Fe}_{m-3} \mathrm{O}_{3 m+3}$ compounds. J. Magn. Magn. Mater., 342, 27-34. DOI: 10.1016/j.jmmm.2013.04.046. 
7. Mazurek, M., Jartych, E., Lisińska-Czekaj, A., Czekaj, D., \& Oleszak, D. (2010). Structure and hyperfine interactions of $\mathrm{Bi}_{9} \mathrm{Ti}_{3} \mathrm{Fe}_{5} \mathrm{O}_{27}$ multiferroic ceramic prepared by sintering and mechanical alloying methods. $J$. Non-Cryst. Solids, 356, 1994-1997. DOI: 10.1016/j. jnoncrysol.2010.05.043.

8. Mazurek, M., Jartych, E., \& Oleszak, D. (2013). Structure and hyperfine interactions of multiferroic $\mathrm{Bi}_{m+1} \mathrm{Ti}_{3} \mathrm{Fe}_{m-3} \mathrm{O}_{3 m+3}$ ceramics prepared by mechanical activation. Nukleonika, 58(1), 143-147.

9. Mazurek, M., Oleszak, D., \& Czekaj, D. (2014). Structure and hyperfine interactions in multiferroic Aurivillius $\mathrm{Bi}_{m+1} \mathrm{Ti}_{3} \mathrm{Fe}_{m-3} \mathrm{O}_{3 m+3}$ compounds prepared by mechanical activation. Mater. Sci.-Poland, 32, 676-681. DOI: 10.2478/s13536-014-0242-9.
10. Mazurek, M., Oleszak, D., Pikula, T., Karolus, M., \& Jartych, E. (2014). Structure and Mössbauer spectroscopy studies of multiferroic mechanically activated Aurivillius compounds. Acta Phys. Pol. A, 126, 975-978. DOI: 10.12693/aphyspola.126.975.

11. Jartych, E., Gąska, K., Przewoźnik, J., Kapusta, C., Lisińska-Czekaj, A., Czekaj, D., \& Surowiec, Z. (2013). Hyperfine interactions and irreversible magnetic behavior in multiferroic Aurivillius compounds. Nukleonika, 58(1), 47-51.

12. Cornell, R. M., \& Schwertmann, U. (1996). The iron oxides. Structure, properties, reactions, occurrence and uses. Weinheim: Wiley-Verlag Chemie. 